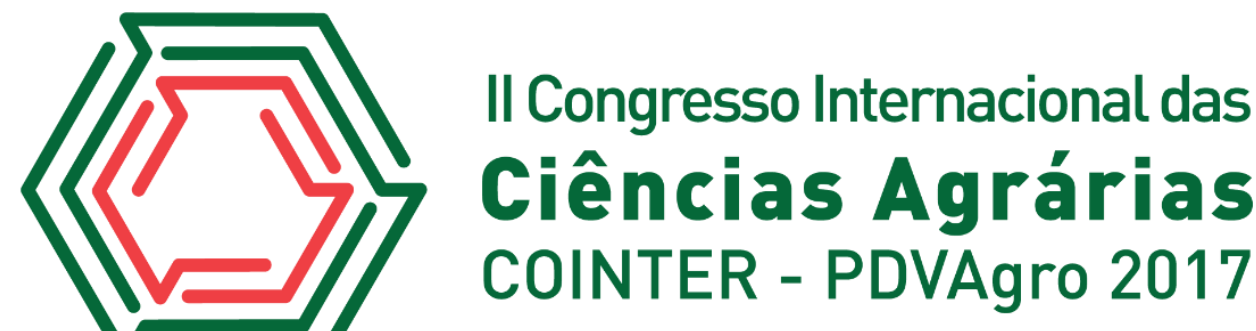

\section{A COMPLEXIDADE DO ESTABELECIMENTO AGRÍCOLA FAMILIAR: UM ESTUDO DE CASO NA COMUNIDADE DE BUCUBARANA PEDRA, REGIÃO DO BAIXO TOCANTINS}

\author{
Apresentação: Comunicação Oral
}

\begin{abstract}
Amanda Rayana da Silva Santos ${ }^{1}$; Elizeth Marques de Souza ${ }^{2}$; Alana Caroline Garcia da Silva $^{3}$; Maria de Nazaré Gonçalves Nogueira ${ }^{4}$; Aldrin Mario da Silva Benjamin ${ }^{5}$
\end{abstract}

\begin{abstract}
Resumo
O estabelecimento agrícola, possui uma natureza multifacetada, por conta disso, sua análise precisa ser metodologicamente adequada, considerando um conjunto de fatores como o espaço físico, as condições, habilidades e tecnologias que o agricultor possui para transformar o meio. Assim como na região amazônica onde os microbiomas são constituídos de diversos ecossistemas com características próprias e harmoniosamente interligadas que os mantêm em perfeito equilíbrio. O objetivo deste trabalho é compreender objetivos propostos pela família e suas estratégias para alcançá-los. A fim de atender o objetivo da pesquisa, optou-se por uso da abordagem sistêmica e utilizou-se um conjunto de ferramentas de investigação como a realização do mapa da propriedade, que teve como intuito, detalhar sobre os sistemas produtivos e de infraestrutura social da propriedade para melhor visualizar a produção anual do agricultor. O sistema de produção do estabelecimento agrícola é composto pelo o subsistema de comando (família), traça estratégias e toma decisões a serem executadas no estabelecimento agrícola para atender aos seus propósitos, o subsistema de cultivo, composto de pimenta do reino e a roça de mandioca, o subsistema de criação com galinha, pato, boi e suíno e subsistema de beneficiamento, etapa da produção antes da comercialização. Conclui- se que as estratégias da família desenvolvem é possível alcançar o objetivo principal, que é poupar, além disso, o lote possui potencial para aumentar a produção através do manejo de plantios existentes na área, entretanto, a força de trabalho no lote é um entrave, pois em determinado momento é necessário contratar mão de obra para realizar as atividades no estabelecimento. O quintal agroflorestal cumpre o papel de suprir algumas necessidades da família e gera excedentes para comercialização. É necessário criar propostas a curto, longo e médio prazo, a longo prazo, por exemplo, seria a organização não só da família do estabelecimento estudado, mas de toda a comunidade, para a comercialização conjunta da pimenta do reino, através da associação.
\end{abstract}

Palavras Chave: Agricultura familiar, Estabelecimento agrícola familiar, Agroecologia

\footnotetext{
${ }^{1}$ Curso de Especialização em Agroecologia, Instituto Federal do Pará- Campus Cametá, santtos.agro@gmail.com

${ }^{2}$ Curso de Especialização em Agroecologia, Instituto Federal do Pará- Campus Cametá, zethmignon@gmail.com

${ }^{3}$ Curso de Especialização em Agroecologia, Instituto Federal do Pará-Campus Cametá, caroline_alana@hotmail.com

${ }^{4}$ curso de Especialização em Agroecologia, Instituto Federal do Pará- Campus Cametá, nazanogueira@hotmail.com

${ }^{5}$ Profo Dr. do curso de Especialização em Agroecologia, Instituto Federal do Pará- Campus Cametá, aldrin.msb@gmail.com
} 


\section{Introdução}

No campo das ciências agrárias, tem sido muito comum o paradigma produtivista-tecnicista no processo de construção do conhecimento, bem como a adoção dos modelos de transferência de tecnologia e dos métodos da Revolução Verde como estratégia de desenvolvimento, a partir do pensamento cartesiano que reduz do todo às partes, como assegurado por Simões; Oliveira (2003). Estas estratégias são classificadas ainda como a adoção de tecnologias de produção, muitas vezes fora do contexto socioeconômico e ecológico dos estabelecimentos, por isso, é chamado de ciência reducionista, principalmente, do ponto de vista clássico consolidado por Descartes que divide o todo em partes e as estuda em separado (Figueiredo e Miguel, 2007).

Em face deste desafio, é necessário compreender que o estabelecimento agrícola, possui uma natureza multifacetada, por conta disso, sua análise precisa ser metodologicamente adequada, considerando um conjunto de fatores como o espaço físico, as condições, habilidades e tecnologias que o agricultor possui para transformar o meio (REIJNTJES et al.1993). Assim como na região amazônica onde os microbiomas são constituídos de diversos ecossistemas com características próprias e harmoniosamente interligadas que os mantêm em perfeito equilíbrio.

Para isso, propõe-se para a análise deste estudo a abordagem sistêmica, em função da crescente complexidade de sistemas organizados e manejados pelo homem, como o estabelecimento agrícola familiar, uma unidade complexa, gerida pela família e que envolve o sistema de produção constituídos de diferentes subsistemas, como o de cultivo, criação, extrativismo e beneficiamento (PINHEIRO, 2000; SCHMITZ; MOTA, 2008). Onde o contexto em que os agricultores estão inseridos, seja este biofísico ou humano, acabam por influenciar nas suas determinações, sendo estes definidos como fundamentais, estratégicos, e/ou práticos, uma vez que o agricultor poderá ter decisões práticas que podem ir de encontro com objetivo principal, anteriormente estabelecido pela família, o que revela que o sistema agrícola é dinâmico e depende do cotidiano do agricultor conforme Nogueira (2009).

Esta abordagem integradora torna-se essencial, pois ao dissecar o mundo em partes isoladas, mental ou fisicamente, perde-se o essencial - a relação entre as partes (CAPRA, 1996). Nesta perspectiva, é necessário o estudo do funcionamento do estabelecimento agrícola familiar, buscando interpretar as inter-relações existentes no sistema de produção e deste com o meio envolvente, para identificar se as estratégias estão em consonância com o objetivo principal da 
família. Portanto, o objetivo deste trabalho é compreender objetivos propostos pela família e suas estratégias para alcançá-los. Sendo assim, é possível compreender que as decisões da família no sistema de produção, não estão vinculadas somente para atender uma demanda do mercado consumidor, mas para uma demanda intrínseca do núcleo familiar.

\section{Fundamentação Teórica}

O estabelecimento agrícola familiar pode ser caracterizado como uma unidade completa administrada pela família, abrangendo o sistema de produção e seus subsistemas de cultivo, criação, extrativismo, beneficiamento e consumo (SCHMITZ \& MOTA, 2008).

O sistema de produção para Dufumier (1985), é o conjunto estruturado das produções vegetais e animais estabelecidos pelo agricultor para garantir a reprodução de sua exploração entre outros objetivos. Além disso, é o resultado da combinação dos meios de produção e da força de trabalho disponíveis em um espaço socioeconômico e ecológico determinado. Além disso, caracteriza-se pela presença de interdependência entre os elementos, a existência de fronteiras mais ou menos permeáveis com o meio envolvente, sua estrutura, ou seja, a combinação de seus elementos em diferentes subsistemas, a existência de diferentes fluxos de energia, produtos e informações, tanto entre os subsistemas como entre o sistema de produção e o meio envolvente e suas finalidades (SILVA, 2013).

O subsistema de cultivo consiste na aplicação de itinerários técnicos em uma superfície de área onde exista homogeneidade de cultivos vegetais. Trata-se de um arranjo espacial e cronológico de populações de cultivos, com entradas de radiação solar, água e nutrientes, e saídas de biomassa com valor agronômico. Vários sistemas de cultivo dentro de uma exploração agrícola compõem um sistema de produção vegetal ou "cropping system" de toda propriedade (MAZOYER, 1989 e DUFUMIER, 1996). Já o subsistema de criação, é um conjunto de elementos em interação dinâmica, organizados pelo homem, com objetivo de valorizar os recursos por intermédio dos animais domésticos (LANDAIS, 1987).

Assim, um sistema de produção agrícola refere-se a um arranjo específico de atividades agrícolas, realizadas por meio da combinação entre terra, força e meios de trabalho com a finalidade de produção vegetal e/ou animal, comum a um conjunto de explorações (PORTO, 2003). Lugar onde o manejo se dá em resposta ao ambiente físico, biológico e sócio econômico e de acordo com os objetivos, preferencias e recursos dos agricultores (REIJINTJES, 1993). 


\section{Metodologia}

O estudo de caso foi realizado no estabelecimento agrícola, na comunidade de Bucubarana Pedra, localizada no município de Cametá, região do baixo Tocantins. Para realização do estudo a modalidade de pesquisa adotada foi descritiva e/ou exploratória, realizando a descrição de uma determinada realidade e como ela se apresenta (TRIVIÑOS, 1987; GIL, 2007).

A fim de compreender o funcionamento do estabelecimento agrícola, optou-se por uso da abordagem sistêmica que de acordo com Burgeois (1983). Para o autor faz-se necessário considera como um sistema, o conjunto constituído por estabelecimento, agricultor e sua família. E em primeira análise, a família fornece ao sistema de produção, o trabalho, em troca do que ela retira como retorno, esse conjunto tem necessidade de capital, mas, saber se ele está afetando à família ou o sistema de produção é secundário. Ou seja, para que o conjunto família-sistema seja analisado corretamente faz-se necessário considerar a situação da família e detectar os seus projetos, tornando-se assim necessária uma abordagem sistêmica, para melhor compreensão do funcionamento dos estabelecimentos agrícolas e de como são tomadas as decisões sobre o uso dos recursos.

A abordagem, utilizou-se um conjunto de ferramentas de investigação baseadas em Verdejo (2006), como a realização do mapa da propriedade, que teve como intuito, detalhar sobre os sistemas produtivos e de infraestrutura social da propriedade para melhor visualizar a produção anual do agricultor. Para a obtenção de informações sobre os diversos componentes dos recursos naturais e os sistemas de produção da família, fez-se uma caminhada transversal, percorrendo o espaço geográfico com várias áreas de uso e recursos diferentes. Ao longo da caminhada anotou-se todos os aspectos que surgem pela observação dos participantes em cada uma das diferentes zonas que se cruzam. O estudo se baseou muito mais em dados qualitativos, uma vez que, dessa forma se pôde analisar mais profundamente as informações e se chegar a uma perspectiva mais aproximada das percepções dos sujeitos.

\section{Resultados e Discussões}

O sistema de produção do estabelecimento agrícola figura 1, é composto pelo o subsistema de comando (família), traça estratégias e toma decisões a serem executadas no estabelecimento agrícola para atender aos seus propósitos, o subsistema de cultivo, composto de pimenta do reino e a roça de mandioca, o subsistema de criação com galinha, pato, boi e suíno e subsistema de beneficiamento, etapa da produção antes da comercialização. 
Figura 1. Mapa do Estabelecimento Agrícola, na comunidade do Bucubarana Pedra, município de Cametá. Fonte: Própria.

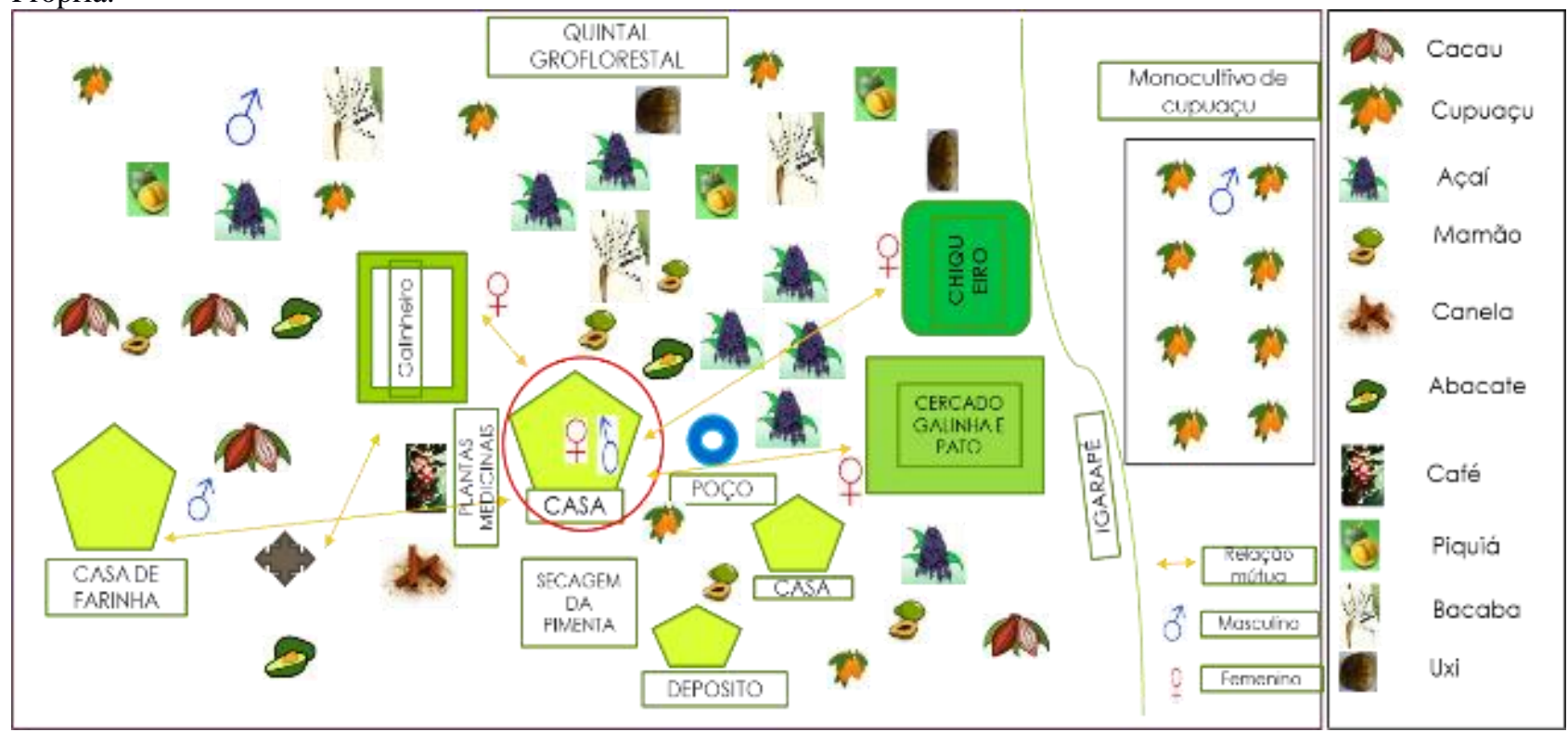

O quintal agroflorestal do estabelecimento oferece uma série de produtos e/ou serviços, diminuindo de forma considerável os gastos da família por meio de produtos que obtêm na propriedade, como o acesso a frutas, plantas medicinais e proteína conforme os estudos de Gazel Filho (2008). Em algumas regiões tropicais, o quintal agroflorestal chega a ser responsável por suprir até $44 \%$ das necessidades de calorias, 32\% de proteínas e de 20 a $35 \%$ do ingresso em dinheiro da família (GEILFUS,1989)

É também uma atividade que foi adquirida com a experiência do agricultor e está diretamente ligada ao seu tempo de permanência no estabelecimento. A experiência, herdada de ancestrais ou adquirida ao longo do tempo, é, geralmente, associada à idade, podendo exercer forte influência nas tomadas de decisão e na gestão do estabelecimento agrícola, com repercussões no desempenho econômico das atividades (BURTON, 2006, p. 486; ONDERSTEIJN; GIESEN; HUIRNE, 2003, p. 34). É ela que faz com que o agricultor tome decisões com base não apenas em fatores econômicos, mas também na dinâmica que envolve o estabelecimento agrícola (ONDERSTEIJN; GIESEN; HUIRNE, 2003, p. 32).

É importante ressaltar, que as áreas do quintal agroflorestal e do monocultivo do cupuaçu não são manejadas para a comercialização, somente para o consumo da família, pois para o agricultor, atualmente não é interessante, pois demandaria mais força de trabalho.

\section{Subsistema de comando (Família)}

A família do estabelecimento agrícola, em estudo, é de origem do município de Cametá, e 
fez parte do surgimento da comunidade Bucubarana Pedra. O lote da família foi herdado e possui título da terra, residem no estabelecimento o casal já com idade média de 50 anos e o neto em torno de 25 anos, os quais desenvolvem as atividades agrícolas do sistema de produção. A esposa é responsável pelas atividades do lar, que também são compartilhadas pelo marido, pelo subsistema de criação e o trato com as plantas medicinais, o esposo e o neto cuidam do manejo do subsistema de cultivo e beneficiamento. Os filhos dos agricultores já são casados e possuem seus próprios estabelecimentos agrícola.

\section{Subsistema de Cultivo}

As atividades do subsistema de cultivo do estabelecimento, baseiam-se na produção culturas anuais como a pimenta do reino e a mandioca e frutíferas, além disso, a pesquisa identificou que o sistema de produção da família está diretamente ligado em atender as demandas no núcleo familiar. Segundo Reijntjes et al. (1993), para entender os sistemas de produção dos estabelecimentos agrícolas a partir de seu contexto humano (sociocultural), é preciso saber o que mudou e o que está mudando, ou seja, conhecer o desenvolvimento histórico, suas causas, efeitos e os agricultores, por considerarem a atividade agrícola como um todo. No início da constituição da família, por exemplo, para promover o sustento e adquirir materiais necessários para sua reprodução social, o agricultor buscou financiamentos bancários para cultivar culturas especificas como o cupuaçu e o cacau, que estavam em alta no mercado, estas áreas hoje ou compõe o quintal agroflorestal ou não estão sendo manejadas Figura 1.

Atualmente, o objetivo central desta família é poupar recursos financeiros para adquirir um automóvel e um casa na cidade de Cametá, os quais irão auxiliar a familiar no deslocamento e no acesso à tratamento de saúde. Para isso, o cultivo da pimenta do reino tem o papel importe para alcançar esta meta, a família fez investimento no plantio da pimenta do reino com recurso próprio, o trabalho nesta área é realizado pelo agricultor e o neto e em período de colheita ou adubação contrata mão de obra com diária equivalente a $\mathrm{R} \$ 40,00$ mais a alimentação. A área abrange 2,5 ha, possui 2.200 pés de pimenta dividido em 5 quadras, figura 2. As duas primeiras quadras são consorciadas, uma somente pimenta do reino (Piper nigrum) espaçamento 2 x 2 com o mamão (Carica papaya) no espaçamento 5x 5 e a outra quadra pimenta do reino com andiroba (Carapa guianensis Aubl.) 20 x 20, cacau (Theobroma cacao) 4x4, coco (Cocos nucifera) 7x7, açaí (Euterpe oleracea) 4x4e castanheira (Bertholletia excelsa) 20 × 20 com característica de Sistema 
agroflorestal- SAF's 5 .

Figura 2. Croqui da área do cultivo de pimenta do reino e Roça. Fonte: Própria.

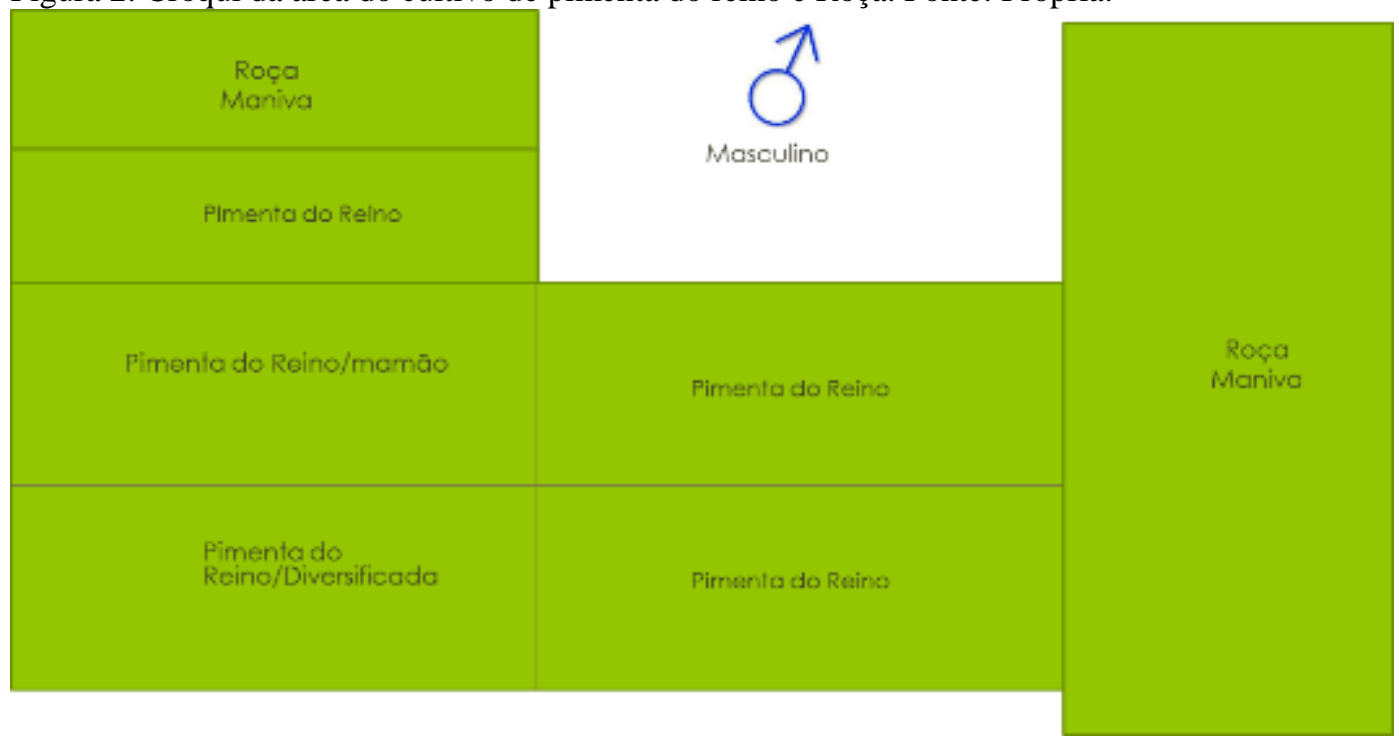

O plantio de pimenta é a principal cultura da unidade produtiva familiar, possui sistema de irrigação projetado pelo agricultor, através da observação em sistemas da área da empresa brasileira de pesquisa agropecuária - EMBRAPA, ele tem linha sim e linha não de encanação, bomba de 1 1 1/2 caixa d'agua de 1000 litros com seis metros de altura. O sistema é acionado em três períodos do dia de cinco as nove da manhã na primeira e na quinta quadra, de duas ás cinco da tarde na segunda quadra e de cinco da tarde as sete da noite na terceira e quarta quadra. A mecanização foi utilizada somente na terceira quadra, a adubação é realizada no início da chuva com $100 \mathrm{~g}$ de NPK $(10,28,20)$, em janeiro é realizado a adubação orgânica com $1 \mathrm{~kg}$ por pé de torta de mamona e em fevereiro utiliza o caroço do açaí e a comercialização desse produto é feita através do atravessador da região.

O cultivo da mandioca (Manihot esculenta Crantz) possui duas áreas de roça, uma com menos de 0,5 ha em área própria e outra área é arrendada com o cultivo de dois tipos de mandioca a branca (Manteiga) e vermelha (saracura), figura 2. O produto do cultivo é a farinha e é destinado ao consumo interno e o excedente é comercializado diretamente ao consumidor final ou na feira de agroecologia e economia solidaria, que ocorre duas vezes ao mês. Assim como na pimenta do reino, a comercialização caracteriza o fluxo financeiro (entrada e saída de recursos) e fluxo de produtos

\footnotetext{
${ }^{5}$ A definição adotada pelo International Center for Research in Agroforestry (ICRAF) é: "Sistema agroflorestal é um nome coletivo para sistemas e tecnologias de uso da terra onde lenhosas e perenes são usadas deliberadamente na mesma unidade de manejo da terra com cultivares agrícolas e/ou animais em alguma forma de arranjo espacial e seqüência temporal" (Nair, 1993).
} 
(beneficiamento dentro da propriedade).

\section{Subsistema de beneficiamento}

O subsistema de beneficiamento, figura 3, está diretamente atrelado ao subsistema de cultivo. O estabelecimento agrícola possui uma asa de farinha que foi adquirida por meio de financiamento coletivo, lá é beneficiado a mandioca para a produção da farinha. Já a pimenta do reino, a secagem é realizada em uma lona que fica na área da frente da casa.

Figura 3. Croqui da casa de Farinha da unidade Familiar. Fonte: Própria.

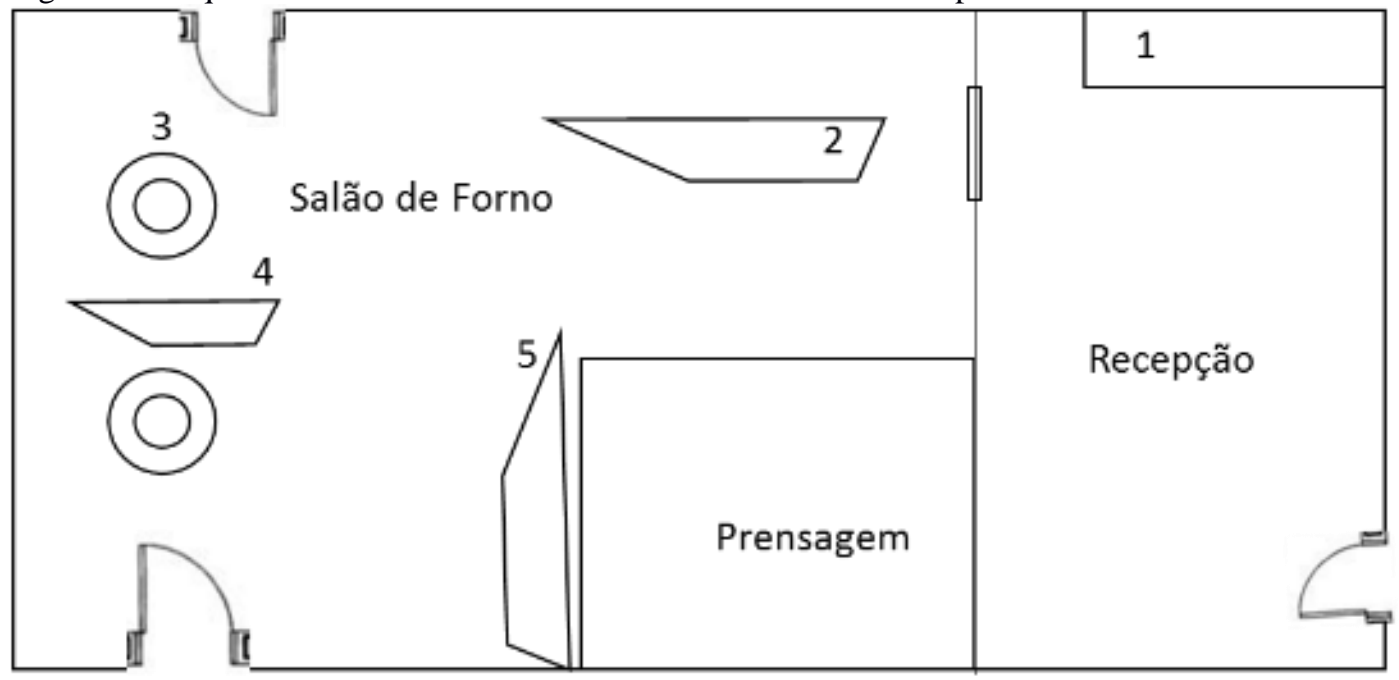

1- tanque de lavagem,2- triturar, 3- Forno, 4- Coagem, 5- Farinha

\section{Subsistema de Criação}

No lote há criações de galinha, patos, um de bovino todos no sistema semiintensivo e suíno no sistema intensivo, nesta propriedade a produção animal se caracteriza como a segunda mais importante. A produção animal na UPF A é utilizada para o consumo da família, salvo algumas vezes que se comercializa, como diz o agricultor 1 :

"Eu crio esses animais porque é melhor para a minha alimentação, principalmente os ovos de galinha que como sou diabética pra mim é mais saudável e serve tanto pro consumo aqui de casa, quanto pra mim vende e dá de presente pras pessoas que eu gosto" (agricultor 1).

A alimentação desses animais é feita com farelo, ração, arroz, milho, sobras de comidas, talos de hortaliças e o resíduo da mandioca são oferecidos ao bovino, as atividades de criação assim como, o trabalho dentro desse sistema de criação é de responsabilidade da mulher.

Deste modo, no estabelecimento agrícola em estudo, o fluxo de energia (trabalho) é realizado $\mathrm{O}$ manejo da área é realizado com mão de obra familiar pelo casal e o neto, havendo 
necessidade de contratação de mão de obra para a apanha e tratos culturais da pimenta. E não há um calendário de trabalho onde seja feita uma divisão da mão de obra para os diversos tipos de cultivo. Além de não haver o controle das horas trabalhadas mensalmente. A produção de farinha, do subsistema de criação e plantas medicinais é destinado ao consumo interno da família e a venda da pimenta do reino atende outras necessidades no fluxo financeiro. Não há um controle com relação ao capital que entra e que sai do sistema. Entretanto, pode ser observado através da obtenção de produtos destinados às despesas familiares como, por exemplo, alimentação e vestuário, que a renda da família aumenta com o cultivo da pimenta. Por fim, o fluxo de informação, a família não recebe assistência técnica e se vale do conhecimento empírico para realizar as atividades e do apoio da associação Paraense de apoio as comunidades carentes- APACC.

Figura 3. Fluxograma de produtos, insumos, matéria, energia e informação. Fonte: Própria

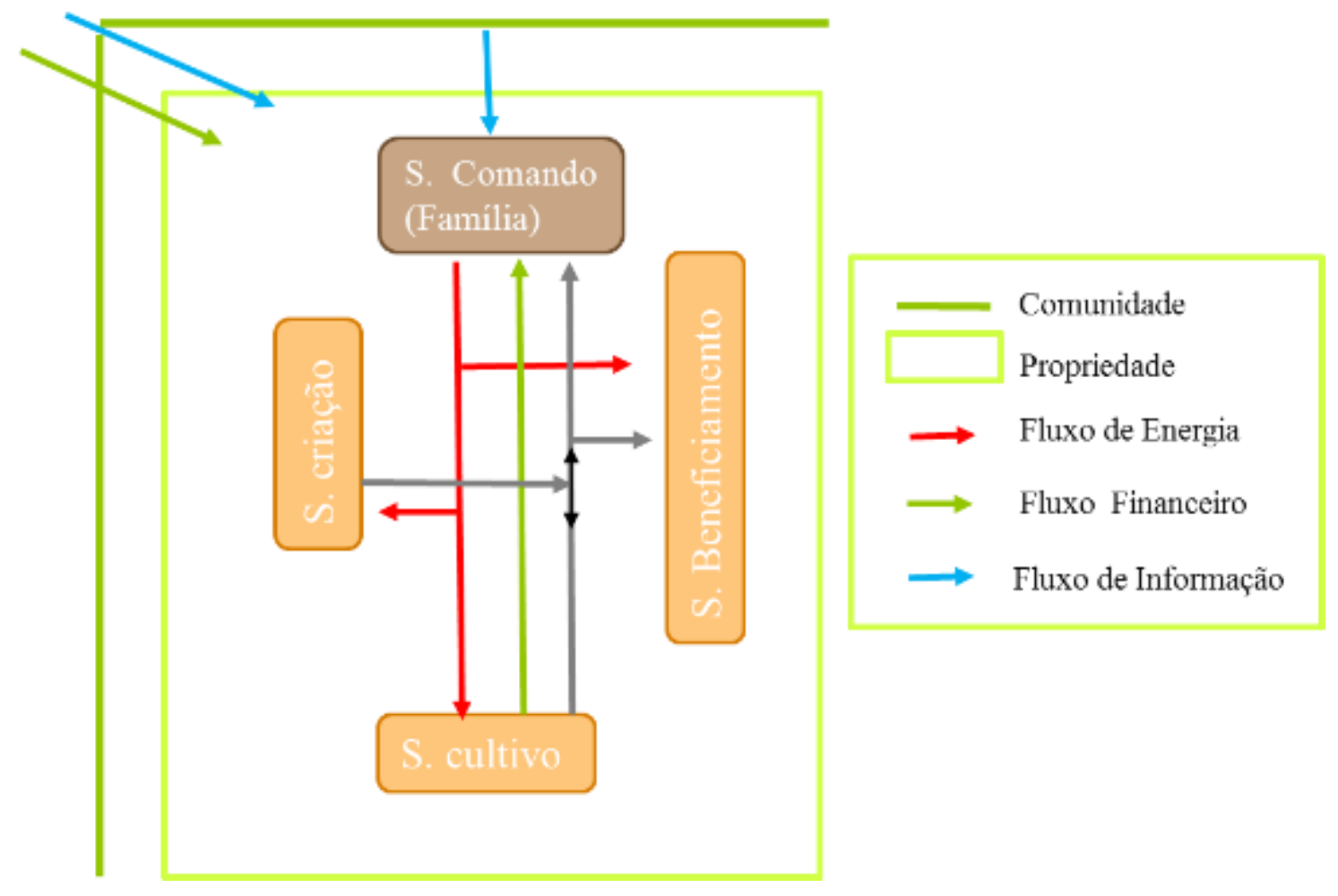

\section{Conclusões}

A partir do exposto no trabalho e observado no estabelecimento agrícola, conclui- se que as estratégias da família desenvolvem é possível alcançar o objetivo principal, que é poupar, além disso, o lote possui potencial para aumentar a produção através do manejo de plantios existentes na área, entretanto, a força de trabalho no lote é um entrave, pois em determinado momento é necessário contratar mão de obra para realizar as atividades no estabelecimento. O quintal agroflorestal cumpre o papel de suprir algumas necessidades da família e gera excedentes para 
comercialização. É necessário criar propostas a curto, longo e médio prazo, a longo prazo, por exemplo, seria a organização não só da família do estabelecimento estudado, mas de toda a comunidade, para a comercialização conjunta da pimenta do reino, através da associação.

\section{Referências}

BOURGEOIS, A. Uma aplicação da noção de sistemas: l'exploitation agricole. Agriscope, $\mathrm{n}^{\circ} 1$. Vol. I, Groupe E.S.A., Angers, 1983. p. 15-31.

BURTON, R. J. F. et al. An alternative to farmer age as an indicator of life-cycle stage: The case for a farm family age índex. Journal of Rural Studies. v. 22, p. 485 - 492, fev. 2006.

CAPRA, F. A Teia da Vida: Uma nova compreensão científica dos sistemas vivos, 1996. Editora Cultrix, São Paulo, Brasil.

DUFUMIER, M. Les projets de développement agricole. Paris : Éditions Karthala - CTA, 1996. $354 \mathrm{p}$.

FIGUEREDO, O. A. T.; MIGUEL, L. de A. Algumas considerações sobre o Desenvolvimento Rural a partir da perspectiva sistêmica. Anais do VII Congresso Brasileiro de Sistemas de Produção, SBSP, Fortaleza, 2007.

GAZEL FILHO, Aderaldo Batista. Composição, Estrutura e Função de Quintais Agroflorestais no Município de Mazagão, Amapá. Aderaldo Batista Gazel FilhoBelém, 2008. 104f.:il. Tese (Doutorado em Ciências Agrárias) - Universidade Federal Rural da Amazônia e Embrapa Amazônia Oriental, Belém, 2008.

GIL, A. C. Como elaborar projetos de pesquisa. 4. ed. São Paulo: Atlas, 2007.

GEILFUS, F. Los sistemas agroforestales. In: El árbol al servicio del agricultor, manual de agroforestería para el desarrollo. Santo Domingo: ENDA: CATIE, 1989. p. 97-245.

LANDAIS, E. Pesquisas sobre sistemas de criação: questões e perspectivas. Tradução de Lívia Navegantes-Alves e Letícia de Freitas Navegantes. Montpellier: INRA, 1987.

NAIR, P. K. R. An introduction to Agroforestry. The Netherlands, Kluwer Academic Publishers with ICRAF. 1993. p. 496.

NOGUEIRA, A. C. N. Estudos de Caso no Território Sudeste do Pará. Um assentamento, uma Família, um Projeto de Vida e o Pronaf: Como a Visão Sistêmica Contribui?. In: Congresso Brasileiro de Agroecologia, 6 e Congresso Latino - Americano de Agroecologia, 2. v. 4. n. 1. Curitiba, PR. 2009.

ONDERSTEIJN, C. J. M.; GIESEN, G. W. J.; HUIRNE, R. B. M. Identification of farmer characteristics and farm strategies explaining changes in environmental management and environmental and economic performance of dairy farms. Agricultural Systems, KN Wageningen, v 78, p. $31-55$, jan. 2003. 
PINHEIRO, S. L. G. sistêmico e o desenvolvimento rural sustentável: Uma oportunidade de mudança da abordagem hard-systems para experiências com soft-systems". Revista Agroecologia e Desenvolvimento Sustentável, Emater, Porto Alegre, v.1, n.2, abr./jun.2000, págs. 27-37".

PORTO, V. H. F. Sistemas agrários: uma revisão conceitual e de métodos de identificação como estratégias para o delineamento de políticas públicas. Cadernos de Ciência e Tecnologia, Brasília, v.20, n.1, p.97-121, jan./abr. 2003.Disponivel em: http://seer.sct.embrapa.br/index.php/cct/article/view/8736/4915. Acesso em: 11/10/2017.

REIJNTJES, C.; HAVERKORT, B.; WATERS- BAYER, A. Agricultura para o futuro: uma introdução a agricultura sustentável e de baixo uso de insumos externos. Trad. John Cunha Comerford. Rio de Janeiro: AS-PTA, 1993.

SILVA, L. M. S. Introdução ao diagnóstico agronômico. Universidade Federal do Pará. Núcleo de Ciências Agrárias de Desenvolvimento Rural - NEAF, 2013.

SIMÕES, Aquiles; OLIVEIRA, Myriam Cyntia César de. O enfoque sistêmico na formação superior voltada para o desenvolvimento da agricultura familiar. In: Coleta Amazônica: Iniciativas em pesquisa, formação e apoio ao desenvolvimento rural sustentável na Amazônia/ Organizador: Aquiles Simões. Belém: Alves ED, 2003. 326 p.

SCHMITZ, H; MOTA, D. M. Agricultura Familiar: categoria teórica e/ou de ação política?. Fragmentos de Cultura. v. 18, n. 5/6, p. 435-446, Goiânia, Brasil, 2008.

TRIVIÑOS, A. N. S. Introdução à pesquisa em ciências sociais: a pesquisa qualitativa em educação. São Paulo: Atlas, 1987.

VERDEJO, M. E. Diagnóstico rural participativo: guia prático DRP. Brasília, DF: MDA/Secretaria da Agricultura Familiar, 2006. 62 p. 32. 